\title{
Los ECA y el Sistema Ambiente
}

Vito Verna

En el presente artículo, el autor analiza los Estándares de Calidad Ambiental (ECA) a la luz del derecho fundamental a la salud y al ambiente, así como sus implicancias en el ordenamiento jurídico para la creación de políticas ambientales. En esa línea de pensamiento, expone los diversos factores que confluyen para que se produzca una verdadera afectación a este derecho y cómo la regulación actual de los Estudios de Impacto Ambiental, constituyen un problema.

Abogado por la Pontificia Universidad Católica del Perú (PUCP), Magister en Economía y Gestión Ambiental, por la Universidad Luigi Bocconi. Actualmente se desempeña como Socio responsable del Área Ambiental de Grau Abogados y Profesor Universitario en la PUCP, ESAN y UPC. 


\section{Los ECA y el Sistema Ambiente}

\section{Derecho al ambiente}

Cuando en el derecho positivo se declara el derecho al medio ambiente, el texto legal se refiere a una entidad sistémica: el medio ambiente. Como es obvio aludir al sistema ambiental no equivale a hablar de sus componentes; el medio ambiente no es el agua, el suelo o el aire, concebidos individualmente, el término alude a todos ellos, y muchos más pensados en interrelación constante y dinámica.

En tal sentido, el ambiente expresa la interacción física, química, biológica y social permanente de un conjunto de elementos vivos y no vivos, naturales o antrópicos, que tienen como escenario nuestro planeta. Aún más, el ambiente no es estático, implica un juego de interrelaciones sistémicas que se producen y reproducen a lo largo del tiempo; por lo tanto, naturaleza y tiempo se entrelazan para crear lo que decidimos denominar ambiente.

Declarar el derecho al ambiente implica además otorgarle una cualificación. Al respecto, los textos normativos utilizan adjetivos tales como "adecuado", "saludable" o "equilibrado", entre otros. Estos calificativos en sí mismos indeterminados, al referirse al sistema ambiental tornan aún más compleja la tarea de establecer si nos encontramos gozando o no del derecho a un medio ambiente adecuado para el desarrollo de la vida.

En tal sentido, el derecho a un ambiente aludirá a un atributo de la naturaleza no determinado con precisión en la norma legal. Por ejemplo, nuestro texto constitucional en su artículo 2, inciso 22 emplea la expresión "medio ambiente equilibrado y adecuado al desarrollo de la vida".

El Tribunal Constitucional ${ }^{1}$ ha mantenido una línea argumentativa respecto de la interpretación del derecho al medio ambiente, la cual se expresa en dos manifestaciones:

'En su primera manifestación, esto es, el derecho a gozar de un medio ambiente equilibrado y adecuado, dicho derecho comporta la facultad de las personas de poder disfrutar de un medio ambiente en el que sus elementos se desarrollan e interrelacionan de manera natural y armónica; $y$, en el caso en que el hombre intervenga, no debe suponer una alteración sustantiva de la interrelación que existe entre los elementos del medio ambiente. Esto supone, por tanto, el disfrute no de cualquier entorno, sino únicamente del adecuado para el desarrollo de la persona y de su dignidad (artículo 1 de la Constitución). De lo contrario, su goce se vería frustrado y el derecho quedaría, así, carente de contenido".

1 Sentencia del Tribunal Constitucional recaída en el Expediente 1848-2011-PA/TC. 
Pero también el derecho en análisis se concretiza en el derecho a que el medio ambiente se preserve. El derecho a la preservación de un medio ambiente sano y equilibrado entraña obligaciones ineludibles, para los poderes públicos, de mantener los bienes ambientales en las condiciones adecuadas para su disfrute. A juicio de este Tribunal, tal obligación alcanza también a los particulares, y con mayor razón a aquellos cuyas actividades económicas inciden, directa o indirectamente, en el medio ambiente".

¿Qué significa un medio ambiente equilibrado? Un artista circense caminando sobre una cuerda, provisto de una vara que lo ayuda a mantenerse en equilibrio puede ayudarnos a comprender este concepto. Mientras la persona, camina naturalmente por la cuerda afirmaremos que se encuentra en equilibrio en relación con la cuerda, en un espacio-tiempo determinado. Sin embargo, si el artista se tambalea peligrosamente sin precipitarse a la red de seguridad, afirmaremos que nuestro personaje mantiene a duras penas el equilibrio y percibiremos un riesgo de caída, es decir de pérdida irreversible del equilibrio.

Pasemos ahora a analizar los significados de nuestra metáfora. El sistema ambiental es representado por la cuerda, la vara, el equilibrista, la velocidad del viento, etc., elementos todos en interacción dinámica y armónica. El bamboleo del equilibrista sobre la cuerda, representa una perturbación en el funcionamiento del ecosistema, que al igual que el equilibrista buscará retomar el equilibrio, a esta propiedad del ambiente la llamamos resiliencia, y, en la medida que la perturbación no sea significativa, será la que le devuelva al ambiente su equilibrio natural.

Por cierto, nuestra metáfora no incluye la caída del equilibrista, esto debido a que el medio ambiente, a diferencia del equilibrista, siempre podrá recobrar el equilibrio, esto solo será una cuestión de tiempo. El problema radica en que puede ocurrir que el nuevo equilibrio ecosistémico no incluya a los seres humanos como especie o a la vida tal y como la conocemos.

El Derecho Ambiental, como rama del Derecho, busca proteger el actual equilibrio ecosistémico, en el cual el ser humano puede vivir y prosperar. Entonces, el derecho humano al ambiente no solo incluye el derecho a que cada individuo goce de las condiciones saludables en su particular entorno vital; sino que, al ser el ambiente una entidad sistémica, el derecho incluye la garantía de que nuestro sistema ambiente se encuentra en equilibrio con el resto de especies que pueblan la tierra.

En efecto, el equilibrio ecosistémico no incluye solo el medio ambiente humano, este es a su vez parte de un sistema aún más grande, que incluye a millones de especies en constante implicación recíproca y con materia inanimada, todo este inmenso juego de interrelaciones constituye en definitiva el objeto del derecho ambiental y del derecho humano fundamental al ambiente. 
Las cuestiones ambientales en realidad son el fruto de la Teoría de Sistemas, la que inspira la definición del Derecho Ambiental que formuló el profesor Raúl Brañes:

"...conjunto de normas jurídicas que regulan conductas humanas que pueden influir de una manera relevante en los procesos de interacción que tienen lugar entre los sistemas de los organismos vivos y sus sistemas de ambiente, mediante la generación de efectos de los que se esperan una modificación significativa de las condiciones de existencia de dichos organismos"'2.

Como en la declaración del derecho subjetivo al ambiente, la definición del derecho ambiental se refiere a la vida, en el primer caso la vida humana y en el segundo la vida en general.

La vida, en general se desarrolla y prospera en la medida que las condiciones ambientales se lo permitan. Los sistemas vivos interactúan con sus entornos físicos, de los cuales obtienen los nutrientes y las condiciones de temperatura, acidez y radiación que le son indispensables para sus procesos vitales, en tal sentido, no es posible entender al ser humano y a la naturaleza como dos entidades separadas, en realidad son una sola, los humanos nos encontramos "inter-penetrados" por la naturaleza, tal como lo subraya el Papa Francisco, en su Encíclica "Laudato Si"3.

La naturaleza nos inter-penetra. Mientras lee estas líneas el aire invade sus pulmones y la hemoglobina de su sangre transporta el oxígeno a todo su cuerpo; sin embargo, podría también transportar monóxido de carbono si eso fuera lo que respira. En tal sentido, preservar los procesos de interacción entre los organismos vivos y sus sistemas de ambiente implica conocer las condiciones físicas, químicas y biológicas (FQB) adecuadas al desarrollo de la vida con la finalidad de poder describirlas, medirlas y conservarlas.

\section{Estándares de calidad ambiental (ECA)}

Los estándares de calidad ambiental (en adelante los ECA) son normas que persiguen precisamente este fin. Establecer, de acuerdo con el estado de ciencia, en forma objetiva y medible las concentraciones de ciertas sustancias en el ambiente que no suponen un riesgo relevante para la salud o el ambiente. En este tipo de normas, también se fijan condiciones ambientales, tales como la acidez o temperatura, que suelen ser importantes para los procesos que garantizan la vida en los ecosistemas.

2 Brañes Ballesteros, R, "El Derecho Ambiental". En: Materiales de enseñanza del Primer Programa Regional Latinoamericano de Capacitación en Derecho y Políticas Ambientales, Ciudad de México, 2004.

3 Papa Francisco, Laudato si, Paulinas, Ciudad del Vaticano, 2015. 
La definición legal de los ECA contenida en el artículo $31^{\circ}$ de la Ley General del Ambiente, Ley $28611^{4}$, es la siguiente:

"ECA es la medida que establece el nivel de concentración o del grado de elementos, sustancias o parámetros físicos, químicos y biológicos, presentes en el aire, agua o suelo, en su condición de cuerpo receptor, que no representa riesgo significativo para la salud de las personas ni al ambiente. Según el parámetro en particular a que se refiera, la concentración o grado podrá ser expresada en máximos, mínimos o rangos".

En tal sentido, los ECA constituyen esencialmente un referente, describen una línea que le permite a un espectador emitir un juicio sobre el estado ambiental de un determinado cuerpo receptor, ya sea este un río, un lago, el mar, la atmósfera o el suelo.

En el Perú, los ECA denominados primarios tienen como punto de referencia a la salud humana, por lo tanto, los valores contenidos en ellos consideran el comportamiento del sistema humano en interacción con su sistema ambiente. Esta interacción, que puede ser denominada como nivel de tolerancia humana a un determinado elemento, es calculada a través de estudios epidemiológicos, los cuales analizan poblaciones humanas durante periodos de muchos años, con la finalidad de determinar la tolerancia humana ante la contaminación crónica; es decir, aquella que es de naturaleza persistente.

También contamos con ECA que son fijados en función del uso que recibirá el recurso suelo o agua y en algunos casos, también con ECA que son establecidos considerando la funcionalidad del ecosistema, como es el caso del ECA-AGUA, categoría 4.

Conviene apuntar que en nuestra realidad, algunas veces los valores máximos de contaminación consignados en el ECA, no necesariamente corresponden a las recomendaciones de salud pública, sino que son "adaptados" en función a consultas con diversos actores gremiales, sociales y técnicos.

Al ser el ECA un referente, y considerando que su definición legal alude al tema de la salud y al medio ambiente, parece clara su relación con los respectivos derechos humanos.

Por otro lado, la Ley General del Ambiente ${ }^{5}$, establece en el mismo artículo 31 antes citado, que:

\footnotetext{
$4 \quad$ Ley General del Ambiente, aprobada mediante Ley 28611, artículo 31.

$5 \quad$ Ley General del Ambiente, aprobada mediante Ley 28611, artículo 31.
} 
"31.2 El ECA es obligatorio en el diseño de las normas legales y las políticas públicas. Es un referente obligatorio en el diseño y aplicación de todos los instrumentos de gestión ambiental.

31.3 No se otorga la certificación ambiental establecida mediante la Ley del Sistema Nacional de Evaluación del Impacto Ambiental, cuando el respectivo EIA concluye que la implementación de la actividad implicaría el incumplimiento de algún Estándar de Calidad Ambiental. Los Programas de Adecuación y Manejo Ambiental también deben considerar los Estándares de Calidad Ambiental al momento de establecer los compromisos respectivos."

Como se aprecia, los ECA guardan estrecha relación con la política ambiental, al ser un referente obligatorio para todos los instrumentos de gestión ambiental. La ley ambiental incluso llega a prescribir que no se otorgará la certificación ambiental cuando el respectivo Estudio de Impacto Ambiental concluya que la implementación de la actividad implicaría el incumplimiento de algún Estándar de Calidad Ambiental.

En conclusión, los ECA por su definición legal, nos trasladan hacia dos ámbitos distintos aunque relacionados; por un lado, nos introduce al mundo de las políticas públicas, debido a que es un instrumento que busca como todos los demás, la realización de la política ambiental; y por otro, a la dimensión del derecho a la salud humana y el ambiente.

A continuación, les propongo una reflexión sobre los vínculos entre los ECA, el derecho al ambiente y la política ambiental.

\section{ECA y los derechos}

Luego de una evaluación del estado de un determinado ecosistema, en la cual se han tomado muestras del agua, del suelo y del aire, lo que tendremos en definitiva son resultados que caracterizaran a cada uno de los elementos mencionados en un determinado lapso de tiempo, tomando como referencia los valores de los ECA. De encontrarse en algunos parámetros valores mayores a los establecidos en los ECA ¿Podríamos afirmar que existe una vulneración al derecho a un ambiente equilibrado?

Creemos que no necesariamente, sin embargo sí habría un dato importante a ser considerado dentro del análisis. Recordemos que se trata de evaluar si la vulneración del ECA pone en riesgo el equilibrio del ecosistema y si este desequilibrio tiene la capacidad de comprometer las funciones que soportan la vida en el ambiente. 
Al respecto, el profesor Nestor Cafferatta ${ }^{6}$ reconoce que la alteración del medio ambiente debe ser relevante, por ende para poder ser considerada como un hecho con implicancias jurídicas en el derecho ambiental supone dos aspectos:

"1) que la acción debe tener como consecuencia la alteración del principio organizativo del paradigma ambiental; esto es alterar el conjunto, de manera que se excluye aquellas modificaciones al ambiente que no tiene efecto sustantivo... y 2) esa alteración sustancial del principio organizativo debe repercutir en aquellos presupuestos del desarrollo de la vida, ya que el medio ambiente se relaciona con la vida...".

En tal sentido, poner en riesgo la capacidad del ambiente de sostener la vida es una conclusión que implica un análisis integral y sistémico, dentro del cual, la vulneración del ECA es una pieza importante a ser considerada. No olvidemos que las mediciones que se confrontan con los ECA se enfocan en los cuerpos receptores, sin considerar la interacción de los elementos conformantes del ecosistema en el tiempo, por lo tanto una evaluación que considera en forma aislada la lectura de los resultados de los monitoreos será siempre parcial.

Otro aspecto importante a ser considerado consiste en poder discriminar la relevancia de los parámetros medidos, no será lo mismo, encontrar que el aire respirable sobrepasa significativamente la concentración estipulada para Benceno, que acreditar que se ha trasgredido la concentración prescrita para Dióxido de Carbono u Ozono Troposférico. No será lo mismo significa exactamente eso, no quiero decir que un parámetro es en absoluto más o menos riesgoso que otro, todo dependerá del juego de interacciones y de los organismos expuestos al contaminante, ya que cada ser vivo tendrá niveles de dosis-respuesta distintos.

Asimismo, el tiempo debe ser una variable a tener en consideración, la dinámica de la atmósfera no es equivalente a la del agua $o$ al suelo, los tiempos de los procesos en cada cuerpo receptor son diferentes, así como la tolerancia a la exposición de los organismos vivos expuestos.

Por último, conviene también reparar en la entidad de la superación del parámetro, ya que suele existir una relación directa proporcional entre concentración de contaminación y el daño real o estimado que puede producirse en los organismos.

Incluso debe considerarse que los ECA pueden estipular concentraciones de contaminantes que para la generalidad de personas son consideradas seguras, pero

6 Cafferatta, Nestor, "Daño Ambiental Colectivo: régimen legal". En: Materiales de enseñanza del Primer Programa Regional Latinoamericano de Capacitación en Derecho y Políticas Ambientales, Ciudad de México, 2004. 
que serán de riesgo para la salud de niños con afecciones respiratorias crónicas o alergias.

En definitiva, proteger el ambiente se traduce en salvaguardar la armonía de las interrelaciones entre los seres y elementos que lo conforman. En este escenario, los ECA son un referente importante en el trabajo de comprender la situación en un momento determinado, pero insuficiente para sustentar posiciones concluyentes sobre cuestiones tan dinámicas y complejas, como el equilibrio ecosistémico o la vigencia o vulneración de un derecho humano fundamental.

Respecto a su relación con la salud pública, la situación, desde nuestra perspectiva es similar.

\section{ECA y salud pública}

De acuerdo con la disciplina científica de Salud Pública, las condiciones ambientales son uno de los determinantes de la salud humana, junto con el estilo de vida de la población, las condiciones sanitarias de las ciudades, entre otros factores.

En tal sentido, las tasas de morbilidad y mortalidad, así como los valores de prevalencia de determinadas enfermedades en una sociedad tendrán que ver con una multiplicidad muy grande de factores; entre los cuales tenemos, la cultura de vacunación de la población, los hábitos alimenticios del país, las costumbres de higiene, y claro está, las características ambientales del agua, el suelo y el aire respirable, entre otras.

Los ECA, como lo expusimos líneas arriba, se enfocan precisamente en las características de las condiciones ambientales, las cuales son un factor importante pero no el único que influye o condiciona la salud humana. Asimismo, el riesgo para la salud requiere para configurarse de tres factores concurrentes, a saber: el contaminante, un vehículo para la transición de éste desde el entorno hacia el interior del organismo humano y, claro está, el ser humano.

Entonces, para poder afirmar que existe un riesgo para la salud (no calcular su entidad, alta, media o baja) debe existir un ser humano expuesto a un contaminante que sea capaz de ingresar a su organismo. Esto debido a que el contaminante por sí solo considerado no es condición suficiente, aunque sí necesaria para que se conforme el riesgo para la salud humana.

Como la ecología, la salud pública es una ciencia que se nutre de muchas otras disciplinas científicas. Para comprender los sistemas que constituyen su foco de estudio requieren el concurso de diversas especialidades, tales como la biología, medicina, química, psicología, economía, física, sociología, etc.

Es posible afirmar en este contexto que los ECA representan un elemento importante para la protección del ambiente y la mejora de las condiciones de vida y salud de la 
población; sin embargo, parece más difícil concluir que la vulneración en la realidad de un parámetro de los ECA se traduce necesaria y automáticamente en un riesgo para la salud de la población, siempre y en todo lugar, incluso donde no exista población o existiendo población no exista posibilidades reales o significativas de que la contaminación ingrese a los organismos humanos.

Por otro lado, debe considerarse que los ECA primarios, al ser una norma pensada en salud humana, contienen concentraciones de contaminación que no necesariamente coincidirán con las características de la naturaleza. Por ejemplo, existen lagunas y suelos naturalmente ácidos, ríos mineralizados y aires con material particulado de origen natural que forman parte del equilibrio ecológico que el Derecho Ambiental protege.

Los ECA constituyen un instrumento relevante para poder estudiar la naturaleza y su relación con el ser humano y las demás especies vivas. Si bien se encuentra demostrada la relación directa entre determinadas concentraciones de metales pesados o material particulado en el aire con las tasas de morbilidad y mortalidad humana; no debe olvidarse que los ECA son un dato importante, pero no el único que debe ser estudiado al buscar conclusiones sobre el estado de los derechos humanos que se relacionan con entidades sistémicas.

Trabajar cuestiones ambientales exige tener conciencia sistémica, la cual se traduce en concebir el fenómeno en su real y compleja dimensión y funcionamiento, analizando toda la información relevante de acuerdo con el conocimiento que deseamos y podemos producir.

\title{
V. Los ECA y las Políticas Ambientales
}

La política ambiental ${ }^{7}$ tiene como objetivo general:

\begin{abstract}
"Mejorar la calidad de vida de las personas, garantizando la existencia de ecosistemas saludables, viables y funcionales en el largo plazo; y el desarrollo sostenible del país, mediante la prevención, protección y recuperación del ambiente y sus componentes, la conservación y el aprovechamiento sostenible de los recursos naturales, de una manera responsable y congruente con el respeto de los derechos fundamentales de la persona".
\end{abstract}

Alcanzar los objetivos fijados en la política ambiental implica el uso de instrumentos de gestión, entre los cuales se encuentran los ECA, los límites máximos permisibles (en adelante los LMP), la evaluación y el estudio de impacto ambiental, la supervisión y fiscalización ambiental, la participación ciudadana en materia ambiental, el ordenamiento territorial, entre otros muchos más.

7 Plan Nacional de Acción Ambiental PLANAA PERÚ: 2011-2021, aprobado mediante Decreto Supremo 014-2011-MINAM, p. 48. Publicado el 09 de julio de 2011. 
Al iniciar este artículo, nos referimos al carácter indeterminado del derecho al ambiente y las dificultades que implica establecer objetivamente cuestiones como ambiente saludable, equilibrado, sostenible, funcional, entre otras, las cuales se utilizan para declarar tanto los derechos como los objetivos de la política ambiental.

Los ECA tienen la enorme virtud de expresar en forma clara valores que nos sirven para evaluar riesgos contra el ambiente o salud humana, no en forma absoluta pero sí poniendo a nuestra disposición información de un determinado momentos que, junto con otras variables, nos permiten aprehender lo que sucede en el ambiente y sus posibles interacciones o consecuencias para los ecosistemas.

Asimismo, establecer el desempeño ambiental de un proyecto, requiere establecer referencias objetivas, como los LMP, la línea de base ambiental, los niveles de fondo y claro esta los ECA.

En conclusión, la política ambiental necesita de los ECA para establecerse, evaluarse, supervisarse y eventualmente fiscalizarse, de lo contrario no sería más que un conjunto de frases que expresan buenas intenciones.

Como hemos expuesto en las líneas precedentes, los ECA mantienen una relación directa con la salud pública y con otros instrumentos de gestión ambiental e incluso permisos administrativos, estas relaciones son las que pasaremos a comentar brevemente a continuación.

\section{ECA y participación ciudadana ambiental}

En el Principio 10 de la Declaración de Río de 1992 se consagra a la participación ciudadana en materia ambiental como uno de los instrumentos más importante para la gestión ambiental. El cuidado de esta entidad compleja denominada ambiente, cuyas infinitas interacciones no llegamos a conocer y mucho menos a explicar por completo; implica aceptar que parte importante de su funcionamiento es y será desconocido y por ende incierto.

Debemos entonces aceptar que emprenderemos la gestión de algo que no conocemos o comprendemos por completo. Es en este contexto, en el cual se encuentra muy presente la incertidumbre, que la participación ciudadana cobra mayor importancia debido a que enriquece el análisis y de alguna manera le otorga mayor legitimidad a la toma de decisión.

Ahora bien, la participación ciudadana ambiental se verá influenciada por los resultados que arrojen los monitoreos ambientales en relación con los ECA. En tal sentido, la capacitación que reciban los monitores comunitarios reviste particular importancia para que se logre comprender las reales implicancias y alcances de esta información. 
En tal sentido, resulta recomendable exponer a la población los resultados de los monitoreos en relación con los ECA, pero no solo ello, sino también las características físicas, químicas y biológicas (FQB) de las emisiones que se descargan al cuerpo receptor, las características (FQB) naturales del cuerpo receptor, así como su variabilidad estacional, la línea de base del proyecto, por citar las más importantes. Asimismo, conceptos como capacidad de carga del ecosistema, toxicidad, riesgo a la salud o resiliencia son también fundamentales.

En resumen, tal como lo mencionamos en líneas anteriores, cuando se trata de cuestiones ambientales la información ambiental debe ser presentada en forma integrada y sistémica. La presentación aislada de los datos ambientales será parcial y podrá ser fuente de falsas percepciones que afectarán negativamente la participación ciudadana.

Recordemos que la percepción de contaminación es fácil de instalar y difícil de remover en la población, de ahí la importancia de realizar los máximos esfuerzos posibles para evitar que los resultados de los monitoreos sean considerados como el único dato importante a considerar y a los ECA como el único referente válido.

\section{ECA, Certificación Ambiental y Estudio de Impacto Ambiental}

En la década de los noventa se concretaron los primeros esfuerzos por implantar una gestión ambiental en el subsector minero. La regulación en ese entonces estableció objetivos de desempeño ambiental a través de LMP para la actividad minero metalúrgica (Decreto Supremo 016-93-EM) y se dispuso que los operadores mineros con proyectos en marcha debían contar con Planes de Adecuación y Manejo Ambiental (PAMA), dirigidos a alcanzar gradualmente los referidos LMP.

En estas etapas iniciales de la gestión ambiental peruana, no existía una relación claramente establecida entre los instrumentos ambientales (LMP y PAMA) y la calidad ambiental del agua el aire o el suelo.

Con la aprobación de la Ley General del Ambiente ${ }^{8}$ en octubre de 2005, se estableció lo siguiente:

"31.3 No se otorga la certificación ambiental establecida mediante la Ley del Sistema Nacional de Evaluación del Impacto Ambiental, cuando el respectivo EIA concluye que la implementación de la actividad implicaría el incumplimiento de algún Estándar de Calidad Ambiental. Los Programas de Adecuación y Manejo Ambiental también deben considerar los Estándares de Calidad Ambiental al momento de establecer los compromisos respectivos".

$8 \quad$ Ley General del Ambiente, aprobada mediante Ley 28611, artículo 31. 
En primer lugar, se erigió a la calidad ambiental y no a los límites de emisión como el objetivo a perseguir por la política ambiental. Acertadamente, la norma ambiental se enfoca en lograr o preservar una calidad ambiental adecuada, en lugar de un desempeño ambiental adecuado, como habría sido la intención en la década de los noventas.

Ahora bien, la calidad ambiental depende de múltiples factores. En el caso de un río, por ejemplo, las características de sus aguas depende del régimen de lluvias (estación seca y lluviosa), la composición y el tipo de suelos de su cauce, los huaicos, la presión de actividades antrópicas, como las ciudades que atraviesa o las industrias que vierten sus efluentes en sus aguas. Por lo tanto, enfocarse en la calidad ambiental del río implicará actuar en cada uno de los elementos que la condicionan. Éste representa uno de los retos más grandes de las políticas ambientales, ya que implican un abordaje sistémico del problema, que se expresará en planes transversales y acciones multisectoriales. Por lo tanto, mejorar la calidad ambiental del río implicará una acción coordinada de múltiples sectores y niveles de gobierno.

Las autoridades sanitarias ocupándose del tratamiento de las aguas servidas, las autoridades extractivas de los efluentes mineros, hidrocarburíferos y energéticos, las autoridades productivas del desempeño ambiental de las industrias, las autoridades municipales manejando adecuadamente los residuos sólidos, las autoridades de flora y fauna ocupándose de la funcionalidad del ecosistema fluvial, las autoridades hídricas regulando el caudal ecológico, y así podríamos continuar por un par de páginas más.

La calidad ambiental, por lo tanto, es el resultado de la acción de muchos elementos unos controlados por el hombre y otros controlados por procesos naturales, sin embargo, la ley ambiental es categórica al sentenciar que no se otorgará la certificación ambiental en caso el EIA de un proyecto individual y determinado concluyera que el emprendimiento no garantizará el cumplimiento de los ECA.

La certificación ambiental es la declaración de viabilidad ambiental que otorga el Estado a un proyecto público o privado. ¿Cuándo un proyecto es viable ambientalmente? Cuando prueba que sus impactos estimados han sido mitigados a niveles aceptables. ¿Qué es aceptable? En caso de extracción de recursos renovables, un nivel de extracción que no ponga en peligros la tasa de reproducción del recurso, en el caso de recursos no renovables, que su explotación sea "razonable"; en el caso de emisiones y efluentes, que se respete la capacidad de carga del cuerpo receptor que los recibe, etc.

Los ECA definen la calidad del cuerpo receptor que no supone un riesgo significativo para la salud o el ambiente; por su parte la capacidad de carga, determina el nivel máximo de contaminación que un cuerpo receptor puede recibir sin que se comprometa su capacidad de asimilación y dispersión. 
Verter un metro cúbico por segundo de efluentes contaminantes en un riachuelo que transporta 2 metros cúbicos por segundo es significativamente mucho más peligroso que verter el mismo metro cúbico en un río que transporta 200000 metros cúbicos por segundo, como es el caso del río Amazonas. Para ambos los ECA serán los mismos pero la capacidad de carga será muy distinta en cada caso.

La calidad ambiental es naturalmente variable, claro está que esta variabilidad puede ser afectada negativamente por las actividades humanas, y también es claro que en algunos lugares las actividades antrópicas serán determinantes (como en la cuenca atmosférica de la ciudad de la Oroya), pero de ninguna manera esta constatación debe ser tomada como absoluta y válida para todos los casos.

Condicionar la aprobación de la certificación ambiental a que se concluya en el EIA que el proyectos cumplirá con los ECA, resulta una elección que podría producir más problemas que soluciones.

En primer lugar, porque no es claro en qué caso se viola el ECA. Me explico: ¿Será cuando se sobrepasa uno, dos, tres, todos o sólo los parámetros de mayor toxicidad? ¿La violación al parámetro debe sea significativa y prolongada en el tiempo o bastará que se supere por minutos u horas? ¿Es posible llegar a una conclusión así de fina en el EIA, instrumento en el cual se consignan proyecciones de emisión y modelos de dispersión de contaminantes de un proyecto?

La variabilidad natural del aíre o el agua ciertamente imponen retos a la necesidad que impone la ley de expresar juicios concluyentes ante monitoreos reales, esta complejidad se ve multiplicada muchas veces, si lo que se evalúa son documentos con estimaciones y modelamientos, que buscarán recrear una situación futura con la información disponible en el presente.

Por otro lado, puede ocurrir que el cuerpo receptor al que se proyecta impactar, no cumpla con los ECA debido a causas naturales o antrópicas, o que las actividades en marcha transiten de una situación de cumplimiento de los ECA a una de incumplimiento, debido a causas naturales o debido a que los ECA han sido modificados hacia niveles superiores de calidad ambiental.

Los ECA son un referente importante para la gestión ambiental y es necesario que lo sigan siendo, por el bien de los ecosistemas y la salud humana, sin embargo debe considerarse también otros referentes y analizarse otras variables.

El pensamiento lineal que equipara la violación del ECA con contaminación o con la vulneración de los derechos humanos o con la no viabilidad ambiental de un proyecto, es equivocado o corre un alto riesgo de serlo, debido a que simplifica y congela una realidad que es esencialmente compleja y dinámica. 
Integrar funcional y armónicamente las actividades humanas a los ecosistemas es el fin último que debe perseguir la gestión ambiental, esta finalidad debe construirse gradualmente con la ayuda de cada vez mejores tecnologías. En tal sentido, la regulación debe alentar y acompañar este proceso siempre en una lógica de progresividad que combine, la acción coordinada y sinérgica de varios instrumentos de gestión ambiental, evitando en lo posible el uso de normas en sí mismas definitorias, salvo que se justifiquen en una amenaza de grave riesgo ambiental o de salud pública.

\section{Conclusiones}

1. El derecho a un medio ambiente adecuado, no solo incluye el particular sistema ambiente de una persona determinada, sino que se extiende al equilibrio ecosistémico.

2. Los ECA son un referente importante para la construcción de una idea sobre el estado del ambiente con relación a la salud, el uso de los recursos y, en algunos casos, la funcionalidad del ecosistema.

3. Los ECA son un referente objetivo, cuyos valores pueden haber tenido en cuenta la salud humana, el uso del recurso (agua o suelo) y en algunos casos la funcionalidad del ecosistema.

4. Evaluar el goce o vigencia del derecho al medio ambiente implica un análisis sistémico, dentro del cual los resultados de los monitoreos relacionados con los ECA son un elemento importante que deberá ser interpretado no en forma aislada sino integrada con el sistema ambiente.

5. El contaminante es un elemento importante del riesgo en salud, sin embargo determinar la realidad y entidad del riesgo implica un análisis que involucra datos adicionales analizados en su integralidad.

6. La información ambiental, que nutre la participación ciudadana, no debe ser presentada en forma aislada, sino en correcta interacción con los demás elementos del ecosistema, con la finalidad de transmitir la realidad del funcionamiento del sistema ambiente.

7. Condicionar la certificación ambiental a que el EIA garantice el cumplimiento del ECA constituye una elección normativa absoluta, difícil de aplicar, que confiere a esta norma una preeminencia absoluta sobre cualquier otra consideración que pudiera estar presente en la evaluación del EIA. 